\title{
Regulation of hTERT by BCR-ABL at multiple levels in K562 cells
}

Juin Hsien Chai ${ }^{1 \dagger}$, Yong Zhang ${ }^{2 \dagger}$, Wei Han Tan ${ }^{1}$, Wee Joo Chng ${ }^{2,3,4}$, Baojie Li $i^{5}$ and Xueying Wang ${ }^{1,2^{*}}$

\begin{abstract}
Background: The cytogenetic characteristic of Chronic Myeloid Leukemia (CML) is the formation of the Philadelphia chromosome gene product, BCR-ABL. Given that BCR-ABL is the specific target of Gleevec in CML treatment, we investigated the regulation of the catalytic component of telomerase, hTERT, by BCR-ABL at multiple levels in K562 cells.

Methods: Molecular techniques such as over expression, knockdown, real-time PCR, immunoprecipitation, western blotting, reporter assay, confocal microscopy, telomerase assays and microarray were used to suggest that hTERT expression and activity is modulated by BCR-ABL at multiple levels.

Results: Our results suggest that BCR-ABL plays an important role in regulating hTERT in K562 (BCR-ABL positive human leukemia) cells. When Gleevec inhibited the tyrosine kinase activity of BCR-ABL, phosphorylation of hTERT was downregulated, therefore suggesting a positive correlation between BCR-ABL and hTERT. Gleevec treatment inhibited hTERT at mRNA level and significantly reduced telomerase activity (TA) in K562 cells, but not in HL60 or Jurkat cells (BCR-ABL negative cells). We also demonstrated that the transcription factor STAT5a plays a critical role in hTERT gene regulation in K562 cells. Knockdown of STAT5a, but not STAT5b, resulted in a marked downregulation of hTERT mRNA level, TA and hTERT protein level in K562 cells. Furthermore, translocation of hTERT from nucleoli to nucleoplasm was observed in K562 cells induced by Gleevec.

Conclusions: Our data reveal that BCR-ABL can regulate TA at multiple levels, including transcription, posttranslational level, and proper localization. Thus, suppression of cell growth and induction of apoptosis by Gleevec treatment may be partially due to TA inhibition. Additionally, we have identified STAT5a as critical mediator of the hTERT gene expression in BCR-ABL positive CML cells, suggesting that targeting STAT5a may be a promising therapeutic strategy for BCR-ABL positive CML patients.
\end{abstract}

\section{Background}

Chronic myeloid leukemia (CML) was the first human cancer to be linked to a consistent chromosomal abnormality [1]. The cytogenetic characteristic of CML is the formation of the Philadelphia chromosome (Ph), by the translocation of chromosome 22 and chromosome 9. As a result, part of the breakpoint cluster region $(B C R)$ gene from chromosome 22 fuses with the $A B L$ gene on chromosome 9. Transcription of this fusion gene results in constitutively active p210 or p190 BCRABL tyrosine kinase [2], which is detected in $95 \%$ of

\footnotetext{
* Correspondence: bchwxy@nus.edu.sg

+ Contributed equally

${ }^{1}$ Department of Biochemistry, Yong Loo Lin School of Medicine, National University of Singapore, 8 Medical Drive, 117597 Singapore, Singapore Full list of author information is available at the end of the article
}

CML and in $20-30 \%$ of adult acute lymphoblastic leukemia (ALL), respectively $[3,4]$. BCR-ABL has a higher tyrosine kinase activity than its cellular counterpart, c-ABL [5]. The deregulated activity of BCR-ABL leads to uncontrolled cell proliferation and reduced apoptosis [6]. BCR-ABL is predominantly localized in the cytoplasm where it interacts with various cellular proteins. These proteins are either phosphorylated by BCR-ABL or promote phosphorylation of their interaction partners, which in turn triggers the activation of numerous signaling pathways, including RAS-RAF, MAPK, PI-3Kinase, c-JUN and c-MYC pathways [7-10].

As the tyrosine kinase activity of BCR-ABL is essential for its transforming ability [11], specific targeting of the BCR-ABL tyrosine kinase provides a promising strategy for CML therapy. Gleevec (Imatinib mesylate or 
STI571), a tyrosine kinase inhibitor which has revolutionized CML therapy, is the current gold standard treatment for CML. Gleevec possesses specificity for Abl, $\mathrm{BCR}-\mathrm{ABL}, \mathrm{c}-\mathrm{Kit}$ and the PDGF receptor. It competitively binds to the ATP-binding site of BCR-ABL and prevents a conformational switch to the oncoprotein's active form. This inhibits BCR-ABL activation through autophosphorylation, and blocks its downstream signal transduction [12]. About 96\% of CML patients exhibited complete hematologic responses (CHR) and major cytogenetic responses (MCR) to Gleevec treatment, and approximately $55 \%$ of ALL patients showed positive responses to Gleevec treatment $[13,14]$.

Human telomerase is a ribonucleoprotein complex consisting of two core components, telomerase reverse transcriptase (human TERT, hTERT) and telomerase RNA template (human TER, hTER). TERT is a class of enzyme that creates single-stranded DNA using singlestranded RNA as a template, whilst TER serves as a template for addition of telomeric repeats (TTAGGG) to DNA strands. By using TER, TERT can cap and protect chromosome ends by adding a six-nucleotide repeating sequence, 5'-TTAGGG (in all vertebrates, the sequence differs in other organisms) to the 3' strand of chromosomes [15]. The expression of hTERT is the rate-limiting determinant of human telomerase activity (TA) and is thought to be a sensitive indicator of telomerase function and activity. However, the means by which TA is regulated remain largely unknown. TA has been observed in $\sim 85 \%$ of all human tumors, suggesting that the immortality conferred by telomerase plays a key role in malignant transformation [16]. TA has been shown to increase in the bone marrow cells of patients with CML during disease progression [17].

Transfection of the catalytic subunit of telomerase, hTERT, into cultured human primary cells transformed with SV40 large $\mathrm{T}$ antigen and $\mathrm{N}$-ras oncogene allows cells to overcome crisis and ultimately achieve malignancy. This suggests that telomerase upregulation may contribute actively to cellular immortalization and tumorigenesis, in human cells [18]. Therefore, telomerase can be considered as an attractive target for cancer diagnosis and anticancer therapy. TA and the expression of telomerase components are regulated at multiple levels, including transcription and post-transcription, accurate assembly, and proper localization [19]. TA can also be regulated at the post-translational level as studies have shown that protein kinase $C$ (PKC) $\alpha$ and $\mathrm{AKT} /$ protein kinase $\mathrm{B}(\mathrm{PKB})$ can upregulate human TA through phosphorylation of hTERT [20,21].

Several studies have reported that Gleevec can regulate TA [22-25]. However, the mechanism by which Gleevec affects TA in BCR-ABL-expressing cells is unclear. Contradicting results were obtained from different studies; some have shown that Gleevec treatment could increase TA and telomere length [26,27], while a more recent study indicated that Gleevec reduced TA in K562, BCR-ABL positive cells [25].

Given that BCR-ABL is the specific target of Gleevec, we surmised that Gleevec affects TA by regulating the expression and activation of telomerase via BCR-ABL. In this study, we investigated the effects of Gleevec on TA in a BCR-ABL positive cell line (K562) and deficient cell lines (HL60 and Jurkat). Our results indicated that Gleevec treatment dramatically inhibits TA and decreases hTERT expression at the mRNA level in K562, but not in HL60 and Jurkat cells. Moreover, knocking down of STAT5a by siRNA resulted in a marked downregulation of $h T E R T$ mRNA level, protein level, and TA in K562 cells. We also found that $\mathrm{K} 562$ cells exhibit a significant increase in hTERT phosphorylation at tyrosine, which was reduced upon Gleevec treatment in K562 cells, but absent in HL60 cells. Furthermore, we also observed the release of hTERT from the nucleoli to the nucleoplasm of Gleevec-treated K562 cells. These results highlight the potential role of $\mathrm{BCR}-\mathrm{ABL}$ in telomerase regulation and imply that BCR-ABL might regulate telomerase expression and activity at the transcriptional level via the JAKSTAT pathway and at the post-translational level through phosphorylation.

\section{Methods}

\section{Cell culture}

K562, KU812, HL60 and Jurkat cell lines, obtained from American Type Culture Collection (ATCC), were cultured in RPMI supplemented with $10 \%$ heat-inactivated FBS, 100 units $/ \mathrm{ml}$ penicillin, $100 \mu \mathrm{g} / \mathrm{ml}$ streptomycin, and $2 \mathrm{mM}$ L-glutamine at $37^{\circ} \mathrm{C}$ in a $5 \% \mathrm{CO} 2$ incubator. Approximately $1.5 \times 10^{5}$ cells were plated in each well of a 6-well plate for drug treatment. BCR-ABL-positive CML patient primary cells (AD155) were obtained with consent and through an approved protocol from the Institutional Review Board (IRB) of the National University of Singapore in accordance with the Helsinki protocol.

\section{Compounds}

Gleevec was a gift from Novartis AG. STAT5 inhibitor (Cat. No. 573108) was obtained from Calbiochem. STAT5 inhibitor was dissolved in dimethyl sulfoxide and diluted to a final concentration of $0.1 \%$ dimethyl sulfoxide in all experiments.

\section{Transfection and infection}

Recombinant lentivirus (GFP-hTERT IRES hygro) was produced by co-transfecting $4 \mu \mathrm{g}$ of pMD.G plasmid, 8 $\mu \mathrm{g}$ of pCMVDR8.91 and $12 \mu \mathrm{g}$ of lentivector into $293 \mathrm{~T}$ cells (ATCC) using Lipofectamine 2000 (Invitrogen). 
Medium containing virus was collected following 24 and $48 \mathrm{~h}$ post transfection and filtered through $0.45-\mu \mathrm{m}$ filters. K562, HL60 and Jurkat cells were incubated with medium containing virus supplemented with $8 \mu \mathrm{g} / \mathrm{ml}$ polybrene for $24 \mathrm{~h}$. Cells were selected with hygromycin for 3-5 days prior to drug treatment.

\section{Gel-based TRAP assay}

Measurement of TA was performed by the PCR-based TRAP (Telomeric repeat amplification protocol) assay, using the TRAPEZE telomerase detection kit (Millipore), according to the manufacturer's instructions. Cells were harvested using ice-cold CHAPS (3-[(3-cholamidopropyl) dimethylammonio]-1-propane sulphonate) lysis buffer and incubated for $30 \mathrm{~min}$ on ice. Cells were clarified by centrifugation at $12000 \mathrm{~g}$ for $20 \mathrm{~min}$ at $4^{\circ} \mathrm{C}$. Telomerase extracts were assayed for TA by TRAP analysis. Each reaction was performed in $50 \mu \mathrm{L}$ reaction mixture containing $10 \mathrm{X}$ TRAP reaction buffer, $50 \mathrm{X}$ dNTP mix, ${ }^{32} \mathrm{P}$-TS primer, TRAP primer mix and Taq polymerase ( 5 units $/ \mu \mathrm{L}$ ). 2step PCR was performed at $30^{\circ} \mathrm{C}$ for $30 \mathrm{~min}$ and was then subjected to PCR amplification for 27 cycles at $94^{\circ} \mathrm{C}$ for 30 sec, $59^{\circ} \mathrm{C}$ for $30 \mathrm{sec}$ each. PCR products were separated by electrophoresis on a 10\% urea gel (National Diagnostics) in a T-REXTM Aluminum Backed Sequencer Model S3S (Owl). Gel was transferred using filter papers into a cassette, incubated for 1 week with phosphoimager and was then scanned using Typhoon Trio Imager (Amersham Biosciences). Quantifications were performed using ImageQuant TL (Amersham Biosciences) and TA was normalized with the 36 bp internal PCR control.

\section{Quantitative telomerase assay}

TA was quantified using telomeric repeat amplification protocol (TRAP) as described by the TeloExpress Quantitative Telomerase Detection Kit (XpressBio). Cells were lysed with $50 \mu \mathrm{l}$ of TeloExpress Lysis buffer and approximately $1 \mu \mathrm{g}$ of DNA was used for real-time PCR. TA in each sample was calculated based on the comparison with the $\mathrm{Ct}$ values of a standard curve generated from 10-fold dilutions of telomerase control (TC) oligo with known copy numbers of the telomeric repeats.

\section{Telomere length assay}

DNA was extracted from the cells using DNeasy Blood \& Tissue Kit (Qiagen). Telomere length analysis was carried out using a non-radioactive TeloTAGGG Telomere Length Assay (Roche) as described by the manufacturer. Approximately $1 \mu \mathrm{g}$ of DNA of each sample was digested with Hinf I/Rsa I enzyme mix and separated by gel electrophoresis. DNA fragments were transferred to nylon membrane (Amersham, GE) by southern transfer and hybridized to digoxigenin (DIG-labeled probe), specific for telomeric repeats. A DIG-specific antibody conjugated to alkaline phosphatase was then used to incubate the membrane and the probe was then visualized by chemiluminescence detection and subsequent exposure to X-ray film (Amsersham, GE). Mean telomeric repeat binding factor (TRF) lengths were determined by comparison to the molecular weight standard provided.

\section{STELA}

XpYp single telomere length assay (STELA) was performed using the methods described by Baird et al. [28]. Total number of telomere bands from the lanes for each sample were pooled and calculated. Telomere shortening was quantified by determining the percentage of telomere bands less than $1.0 \mathrm{~kb}$ to the total number of bands in the sample.

\section{RT-PCR}

One step RT-PCR was performed using the Qiagen One Step RT-PCR kit following manufacturer's protocol. The following primers were used: 5'-CGTGGTTTCT GTGTGGTGTC-3' (human TERT forward primer) and 5'-CCTTGTCGCCTGAGGAGTAG-3' (human TERT reverse primer), 5'-GCCTTCCACCGTTCATTCTA-3' (human TER forward primer) and 5'-GCTGACAGAGCCCAACTCTT-3' (human TER reverse primer), 5'-GAGAGACCCTCACTGCTG-3' (GAPDH forward primer) and 5'-GATGGTACATGACAAGGTGC-3' (GAPDH reverse primer). PCR products were run on $2 \%$ agarose gel and viewed under UV Gel Doc (BioRad). Quantifications were performed using Quantity One (BioRad).

\section{Real-time PCR}

Reverse transcription was performed using the Promega RT-PCR kit and oligo dT primer as per manufacturer's protocol (Promega). Real-time PCR was performed using Brilliant SYBR Green qPCR Master Mix on the Rotorgene real-time system (Qiagen). The following primers were used for real-time PCR: 5'-GGAGCT GGTGGTTGACTTTC-3' and 5'-CTCCGATTCAGTCC CTTCTG-3' (human BCL2), 5'-ATACCATGATAGCG CCCTTG-3' and 5'-AATCACAGCGAACCTCTGCT-3' (human PI3KCG), 5'-CCCTCGGTGTCCTACTTCAA-3' and 5'-AGGAAGCGGTCCAGGTAGTT-3' (human CCND1), 5'-TGCCAAGAGTCTAGCCCAGT-3' and 5'TCCACTGTTCATAGGGCACA-3' (human PFKFB4), 5'-ATGCGACAGTTCGTGGCTCA-3' and 5'-ATCCCC TGGCACTGGACGTA-3' (human TERT), 5'-GTGGAC CTGACCTGCCGTCT-3' and 5'-GGAGGAGTGGG TGTCGCTGT-3' (human GAPDH). Data were analyzed using the $\Delta \Delta \mathrm{CT}$ method. 


\section{Western blotting}

Cells were harvested for protein at different time points. Briefly, cells were resuspended in $50 \mathrm{mmol} / \mathrm{L}$ Tris $-\mathrm{HCl}$ (pH 7.4), $250 \mathrm{mmol} / \mathrm{L} \mathrm{NaCl}, 5 \mathrm{mmol} / \mathrm{L}$ EDTA, and $0.1 \%$ NP40 containing protease and phosphatase inhibitors. Lysates were cleared by centrifugation at 14,000 rpm for $10 \mathrm{~min}$, and samples were run on SDS-PAGE gels. Western blotting was performed with the following antibodies: rabbit anti-BCR-ABL (Cell Signaling), rabbit antihTERT (Epitomics), rabbit anti-pSTAT5 (Tyr694) C11C5 (Cell Signaling), mouse anti-pTyr (Millipore) and phospho-abl (Tyr412) (Millipore). Mouse anti- $\alpha$-tubulin (Sigma) or Horseradish peroxidase (HRP)-conjugated mouse anti- $\beta$-actin (Abcam) or mouse anti-GAPDH (Cell Signaling) were used as loading controls. Immunostaining was detected using ECL Plus Detection Reagent (GE Healthcare).

\section{Immunoprecipitation}

After Gleevec treatment, K562 and HL60 cells were rinsed in cold PBS and lysed in a RIPA buffer. Cell lysate was kept on ice for $10 \mathrm{~min}$ and centrifuged for 10 min at $12,000 \mathrm{~g}, 4^{\circ} \mathrm{C} .2 \mu \mathrm{l}$ of anti-hTERT antibody (Abcam) was added to $200 \mu \mathrm{l}$ of cell lysate and incubated overnight at $4^{\circ} \mathrm{C} .20 \mu \mathrm{l}$ of protein $\mathrm{A}$ agarose beads (50\% bead slurry) was added for $3 \mathrm{~h}$ at $4^{\circ} \mathrm{C}$. Samples were centrifuged for $30 \mathrm{sec}$ at $4^{\circ} \mathrm{C}$. Pellets were washed five times with lysis buffer. Laemmli buffer was added and samples were boiled at $100^{\circ} \mathrm{C}$ for $5 \mathrm{~min}$. Samples were centrifuged for $1 \mathrm{~min}$ at 14,000 g, and supernatants analysed by Western blotting. The tyrosine phosphorylation level of hTERT was examined by anti-phosphotyrosine antibody (Millipore).

\section{siRNA transfection}

siRNA oligos for knockdown of endogenous human STAT5a and STAT5b proteins and Negative Control (Scramble) siRNA were purchased from Ambion. Transfections were performed by Amaxa nucleofection (Lonza), by using program T-016 (K562 cells) or T-019 (HL60 cells) as per manufacturers' instructions.

\section{Luciferase reporter assay}

HeLa cells were seeded in 24-well plates and co-transfected with $h T E R T$ promoter $(-3915 \sim+40)$ luciferase construct (pGL3- hTERT), pMX-STAT5a, pMXSTAT5b, or pMX (vector control) using Lipofectamine 2000 (Invitrogen). Forty-eight hours following transfection, cells were harvested and subjected to the luciferase assay using the dual-luciferase reporter assay kit (Promega). The pRL-SV40 driving Renilla reniformis luciferase was included in each transfection as a control to normalize the transcriptional activity of hTERT promoter fragments. Standard deviations were derived from three independent experiments.

\section{Confocal microscopy}

K562, HL60 and Jurkat cells were infected with GFPhTERT IRES hygro expressing virus. Cells were cytospun according to Shandon Cytospin Program and then fixed with $2 \%$ paraformaldehyde in PBS, and permeabilized with $0.2 \%$ Triton X-100 in PBS. Immunostaining was performed using primary antibodies against fibrillarin (Cell Signaling) followed by appropriate secondary antibody conjugated with Alexa Fluor 568 antibody (Invitrogen). DNA was visualized with $0.2 \mu \mathrm{g} / \mathrm{mL}$ of 4',6-diamidino-2-phenylindole (DAPI) and all images were analyzed using Olympus Fluoview FV100 microscope with $60 \times$ objective.

\section{Illumina microarray analysis}

RNA was isolated from K562 and HL60 cells, non-treated or treated with $1 \mu \mathrm{M}$ of Gleevec for $8 \mathrm{~h}$, using the RNeasy kit with on-column DNase digestion (Qiagen). Quality of RNA from each sample was assessed using the RNAnalyzer (Biorad), all with an RNA integrity number $>7$, and $500 \mathrm{ng}$ of RNA was converted to cRNA using the Illumina TotalPrep RNA Amplification kit (Ambion). Labeled cRNA was prepared and hybridized overnight for $18 \mathrm{~h}$ to Illumina HumanRef-8_V2 array containing 18,126 human genes, which was then washed and stained with streptavidin-Cy3 (AmershamPharmacia Biotech) according to the manufacturer's guidelines (Illumina) and arrays were scanned on a BeadArray Reader (Illumina). Using the Partek software, statistical significance of global gene expression levels were analyzed by Analysis of Variance (ANOVA) at false discovery rate (FDR) $<0.05$ and were defined as genes with two-fold up or downregulation. Microarray data is available in MAIME-compliant form at NCBI Gene Expression Omnibus (http://www.ncbi.nlm.nih. gov/geo) under accession number GSE26821.

\section{Results}

Gleevec specifically inhibits TA in BCR-ABL positive cells Since telomerase plays a critical role in tumorigenesis, the effects of different drugs on TA are of potential importance [29]. In this study, we found that Gleevec significantly decreased K562 cells viability and proliferation within $48 \mathrm{~h}$ (Additional file 1: Figure S1). This result is in agreement with previous studies, which demonstrated that the inhibitory effect of Gleevec on leukemia cells is at least partially due to its inhibitory effect on telomerase activity $[23,25,30]$.

In order to attest the mechanism of Gleevec on TA and its regulation, TA of BCR-ABL positive (K562) and 


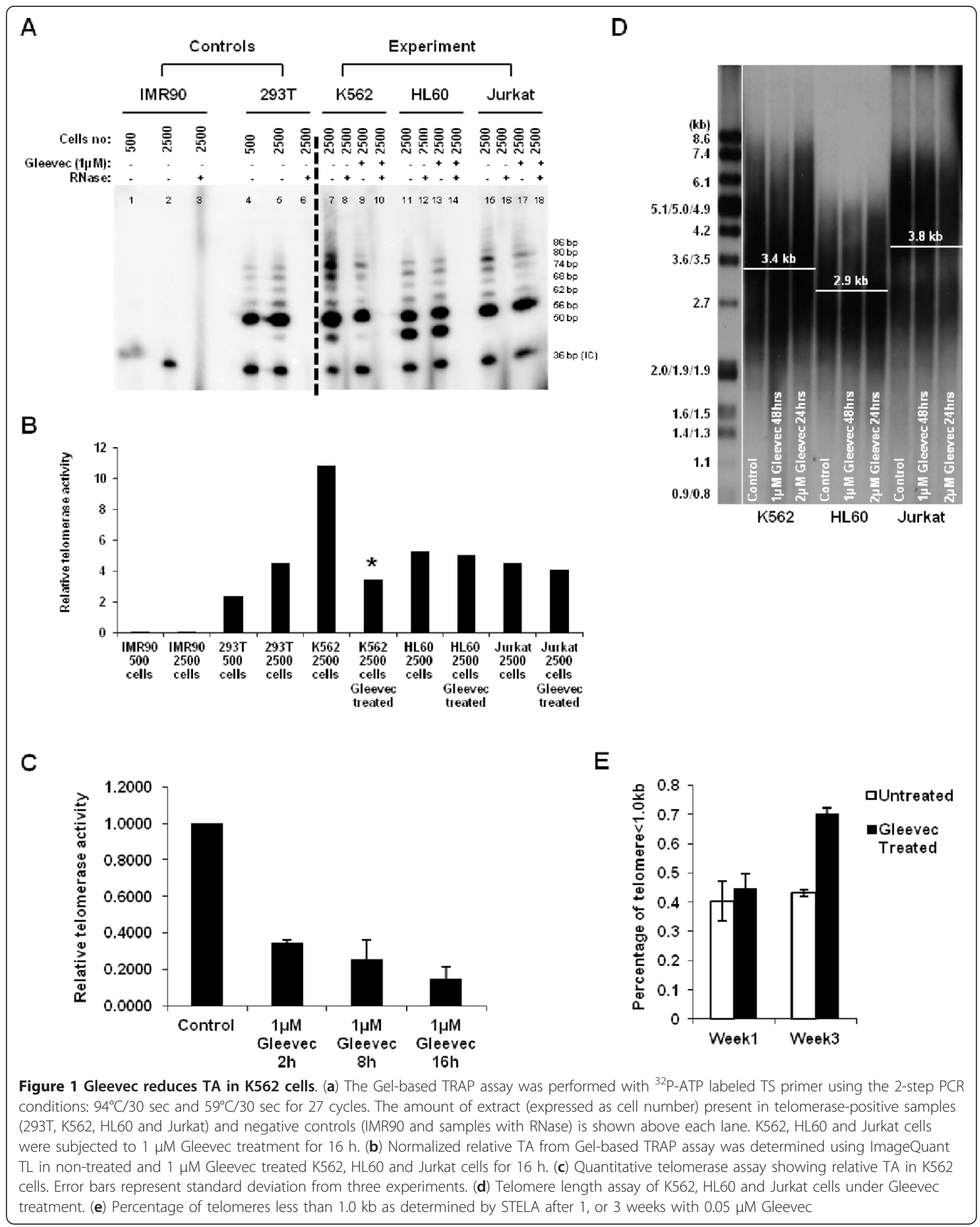


deficient (HL60 and Jurkat) cells were assessed by gelbased Telomeric Repeat Amplification Protocol (TRAP) assay following $16 \mathrm{~h}$ of Gleevec treatment. TRAP results showed that K562 cells have a significantly higher TA ( $50 \%$ higher) than HL60 or Jurkat cells (Figure 1a and 1b). However, upon $1 \mu \mathrm{M}$ Gleevec treatment, we observed that TA in K562 cells was reduced by $~ 70 \%$. Nevertheless, this effect of Gleevec was not evident in BCR-ABL deficient cells, i.e., HL60 and Jurkat cells (Figure 1a and $1 \mathrm{~b}$ ). On the other hand, TRAP results also indicated that Gleevec treatment had no effect on telomerase processivity in both BCR-ABL positive and deficient cells (Figure 1a). To further confirm the effect of Gleevec on TA in K562 cells, Quantitative Telomerase Assay was also performed. Treatment of $1 \mu \mathrm{M}$ Gleevec for $2 \mathrm{~h}$ resulted in a significant reduction of TA in K562 cells, which was consistent with the gel-based TRAP assay result (Figure 1c). To avoid cell specific effects, another BCR-ABL positive cell line, KU812 and BCRABL positive CML patient cells, AD155, were used to determine Gleevec effect on TA. Our results also showed a significant decrease in TA in KU812 and AD155 cells under Gleevec treatment (Additional file 1: Figure S2). These results indicate that Gleevec specifically inhibits TA in BCR-ABL positive cells, i.e., K562, KU812, and AD155 cells.

To investigate the effect of Gleevec on telomere length, K562, HL60, and Jurkat cells were treated with Gleevec and telomere lengths were quantified using Southern Blotting. Telomere signals appeared as a broad smear of densities. Mean telomere length of K562, HL60, and Jurkat cells were $3.4 \mathrm{~kb}, 2.9 \mathrm{~kb}$ and $3.8 \mathrm{~kb}$, respectively (Figure 1d) and the result showed that there was no significant change in telomere length upon Gleevec treatment. This could presumably be due to the short treatment period of cells with Gleevec, preferred within $24 \mathrm{~h}$.

We next questioned if Gleevec would induce a longer term effect on telomere length of K562 cells. We used subapoptotic concentrations of Gleevec [31] to treat the cells for a longer period. K562 cells were cultured for up to 3 weeks with $0.05 \mu \mathrm{M}$ Gleevec. Cells were collected at week 1 and week 3 and then subjected to telomere length determination using the single telomere length assay (STELA) [28]. Telomere shortening was quantified by determining the percentage of telomere bands less than $1.0 \mathrm{~kb}$ to the total number of bands in the sample. As shown in Figure 1e, Gleevec did not induce visible telomere length shortening after 1 week treatment. After 3 weeks treatment, however, K562 cells displayed a significantly increased proportion of shortened telomeres $(<1.0 \mathrm{~kb})$, suggesting that Gleevec has a long-term effect on telomere length via inhibiting TA.

\section{Gleevec specifically downregulates $h T E R T$ mRNA level in BCR-ABL positive cells}

To elucidate the mechanism of Gleevec's inhibitory effect on TA in BCR-ABL positive cells, RT-PCR was performed to quantify $h T E R T$ and $h T E R$ mRNA levels in K562, HL60, and Jurkat cells. The basal level of hTERT is the same throughout the three cell lines, although the level of $h T E R$ is higher in BCR-ABL positive K562 cells as compared to BCR-ABL deficient HL60 and Jurkat cells. Gleevec treatment for 16-hour significantly reduced the $h T E R T$ mRNA level in K562 cells compared to the non-treated control, but the same Gleevec treatment had no effect on $h T E R T$ mRNA level in BCR-ABL deficient HL60 or Jurkat cells (Figure 2a). Same samples were subjected to real-time PCR for validation of the result shown in RT-PCR. Real-time PCR result also showed reduced $h T E R T$ mRNA level, by $\sim 60 \%$, upon 16-hour treatment in K562 cells, which showed consistency with the RT-PCR result (Additional file 1: Figure S3). In addition, $h T E R T$ mRNA level was gradually reduced with increasing Gleevec incubation time, suggesting a direct positive correlation between Gleevec targeted pathway and $h T E R T$ expression (Figure $2 b)$. However, $h T E R$ mRNA levels remained unchanged in both the BCR-ABL positive and deficient cells treated with Gleevec (Figure 2a). These data suggested that Gleevec inhibited TA rapidly by specifically reducing hTERT mRNA level in BCR-ABL positive K562 cells. Similar result was also shown in KU812 cells by using real-time PCR (Additional file 1: Figure S4).

We next conducted a microarray analysis to examine the gene expression changes between control and $8 \mathrm{~h}$ Gleevec-treated cells. We first compared K562 non-treated cells with HL60 non-treated cells and then further analysed the comparison between K562 Gleevec-treated cells with K562 control cells. From our microarray analysis, we noted distinct profiles of gene expression changes in both sets of comparisons. In K562 control cells versus HL60 control cells, a total of 855 and 2182 genes were significantly upregulated and downregulated, respectively (with a $p$ value $<0.05$ and fold change $>$ or $<2)$. When comparing K562 Gleevec-treated cells versus K562 control cells, 1114 genes were significantly upregulated and 113 observed to be significantly downregulated (with a $p$ value $<0.05$ and fold change $>$ or $<2$ ) (Additional file 1: Figure S5). Overlapping genes are listed in Additional file 1 (Table S1). We next sought to identify the gene sets that were enriched in K562 Gleevec-treated group versus $\mathrm{K} 562$ control group. This was achieved through the comparison of our array data against known curated gene sets available from Molecular Signatures Database (MSigDB). In agreement to our Western results, our gene set analysis revealed that a 
A
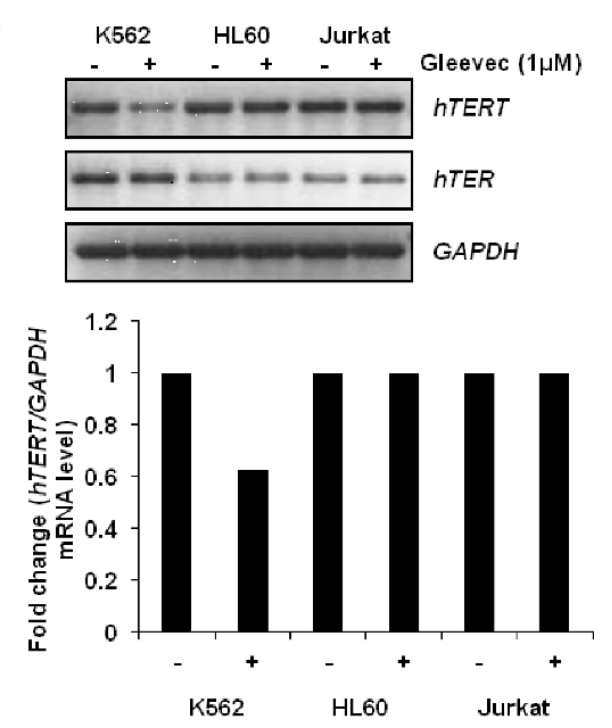

B
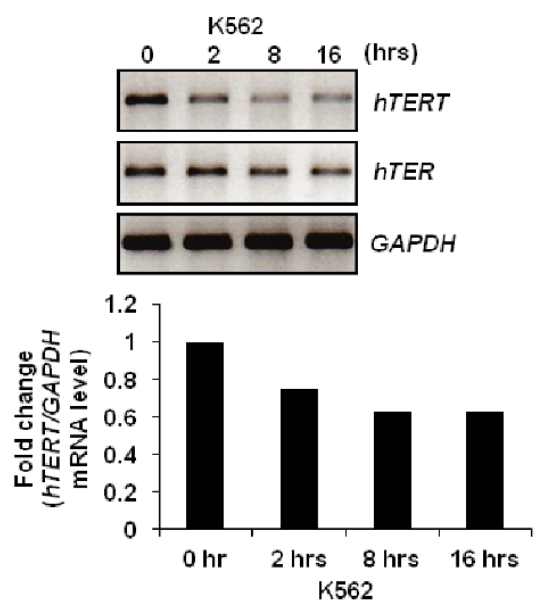

C

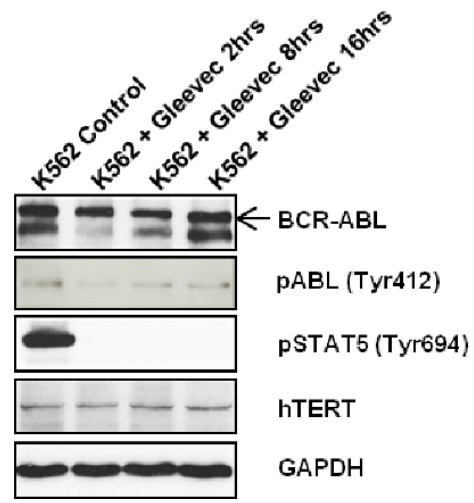

Figure 2 Gleevec reduces $h$ TERT mRNA level in K562 cells. (a) 1 $\mu \mathrm{M}$ Gleevec treatment for $16 \mathrm{~h}$ inhibits hTERT mRNA level in K562 but not in HL60 and Jurkat cells. Upper Panel: RT-PCR image; Lower Panel: Quantitation of the RT-PCR image. (b) hTERT mRNA level in K562 cells was gradually reduced with increased incubation time upon $1 \mu \mathrm{M}$ Gleevec treatment. Upper Panel: RT-PCR image; Lower Panel: Quantitation of the RT-PCR image. (c) Endogenous proteins expression level of K562 cells under $1 \mu \mathrm{M}$ Gleevec treatment for 2, 8 and $16 \mathrm{~h}$ number of downregulated genes in K562 Gleevectreated set were grouped under the JAK/STAT pathway (Table 1A). Three genes were selected from Table $1 \mathrm{~B}$ and further validated by real-time PCR (Additional file 1: Figure S6-8, Table S2). In particular, we noted a downregulation of PIK3CG (also known as $P I 3 K)$, a gene coding for the catalytic component of phosphoinositide-3-kinase (PI3K), a nonreceptor tyrosine kinase (Table 1B). A significant difference of almost 3 folds downregulation was observed when $\mathrm{K} 562$ cells were treated with Gleevec as compared to $\mathrm{K} 562$ control cells (Additional file 1: Figure S7). Though we did not observe any significant downregulation of $h T E R T$ mRNA in microarray analysis, real-time PCR results showed considerable hTERT mRNA downregulation in Gleevec-treated K562 cells (Additional file 1: Figure S9, Table S2). The discordance of $h T E R T$ gene expression result may be explained by the decreased sensitivity of the microarray gene expression change compared to realtime PCR. But, we noted many upregulated genes that were enriched in gene sets involved in telomere maintenance, telomere extension and telomere ends packaging (Additional file 1: Table S3A \& B).

Next, we determined whether Gleevec could inhibit hTERT expression at the protein level in K562 cells treated with $1 \mu \mathrm{M}$ of Gleevec at different time points. Surprisingly, there was no significant alteration in the protein expression level of hTERT upon $16 \mathrm{~h}$ of Gleevec treatment (Figure 2c). This could be due to a short half-life of $h T E R T$ mRNA $(\sim 2 \mathrm{~h})$ [32] compared to the long half-life of hTERT protein $(\sim 24 \mathrm{~h})$ in $\mathrm{K} 562$ cells (Additional file 1: Figure S10) [33], resulting in an indirect correlation between the protein level and the transcriptional level. We have extended the Gleevec treatment beyond $24 \mathrm{~h}$, and we did not observe any marked change in hTERT protein expression level at 24 and $36 \mathrm{~h}$. There is a slight decrease in hTERT protein level at $48 \mathrm{~h}$. This suggested that Gleevec has no significant effect on reducing the rate of hTERT degradation in short-term treatment (Additional file 1: Figure S11). Besides, we observed and confirmed in Figure 2c that Gleevec reduces the tyrosine kinase activity of BCR-ABL by abolishing the phosphorylation of BCR-ABL and therefore eliminates the phosphorylation of STAT5 (Signal Transducer and Activator of Transcription 5). STAT5 is activated by BCR-ABL and is implicated in the pathogenesis of CML. Since STAT5 is a well-known transcriptional activator and has been proven to function as a transcriptional regulator of $h T E R T$ [34], these evidences led us to hypothesize that BCR-ABL plays a critical role in regulation of hTERT expression through the STAT5 signaling pathway. 
Table 1 Comparison between K562 Gleevec-treated group versus K562 control group.

\begin{tabular}{|c|c|c|c|}
\hline \multicolumn{4}{|c|}{ A. K562 Gleevec-treated group versus K562 control group } \\
\hline Function & Enrichment Score & Enrichment $p$-value & $\begin{array}{l}\text { \# genes in list, in } \\
\text { group }\end{array}$ \\
\hline $\begin{array}{l}\text { KEGG JAK STAT } \\
\text { SIGNALING PATHWAY }\end{array}$ & 12.616000 & 0.000003 & 8 \\
\hline ST STAT3 PATHWAY & 6.219490 & 0.001990 & 2 \\
\hline \multicolumn{4}{|c|}{ B. JAK-STAT Signaling Pathway } \\
\hline Gene Symbol & Definition & $\begin{array}{l}p \text {-value(K562 Treated vs. } \\
\text { K562 Control) }\end{array}$ & $\begin{array}{l}\text { Fold-Change } \\
\text { (K562 Treated vs. } \\
\text { K562 Control) }\end{array}$ \\
\hline BCL2L1 & $\begin{array}{l}\text { Homo sapiens BCL2-like } 1 \text { (BCL2L1), nuclear gene encoding } \\
\text { mitochondrial protein, transcript variant 1, mRNA. }\end{array}$ & 0.000076 & -2.336810 \\
\hline $\mathrm{ClSH}$ & $\begin{array}{l}\text { Homo sapiens cytokine inducible } \mathrm{SH} \text {-containing protein (CISH), } \\
\text { mRNA. }\end{array}$ & 0.000754 & -2.926860 \\
\hline CCND1 & Homo sapiens cyclin D1 (CCND1), mRNA. & 0.000964 & -9.480380 \\
\hline SPRED1 & $\begin{array}{l}\text { Homo sapiens sprouty-related, EVH1 domain containing } 1 \text { (SPRED1), } \\
\text { mRNA. }\end{array}$ & 0.001425 & -3.138930 \\
\hline SOCS1 & Homo sapiens suppressor of cytokine signaling 1 (SOCS1), mRNA. & 0.003518 & -2.455500 \\
\hline$\overline{\text { IL6 }}$ & Homo sapiens interleukin 6 (interferon, beta 2) (IL6), mRNA. & 0.004541 & -2.036640 \\
\hline PIK3CG & $\begin{array}{l}\text { Homo sapiens phosphoinositide-3-kinase, catalytic, gamma } \\
\text { polypeptide (PIK3CG), mRNA. }\end{array}$ & 0.005740 & -2.292180 \\
\hline PIM1 & Homo sapiens pim-1 oncogene (PIM1), mRNA. & 0.006760 & -2.343000 \\
\hline
\end{tabular}

(a) Gene set analysis showing enrichment of gene sets under JAK/STAT pathway. These gene sets showed the number of genes that are downregulated in this pathway in K562 Gleevec-treated cells. (b) List of downregulated genes related to JAK/STAT pathway in K562 Gleevec-treated cells

\section{STAT5a plays a critical role in hTERT gene expression in K562 cells}

STAT5 inhibitor was used to examine the specific role of STAT5 in the expression of $h T E R T$ mRNA in BCRABL positive or negative cells. K562 and HL60 cells were treated with either STAT5 inhibitor or vehicle. After $48 \mathrm{~h}$, cells were subjected to determination of hTERT mRNA and TA. Real-time PCR revealed that STAT5 inhibitor treatment caused a significant decrease in expression of hTERT in K562 cells, but not in HL60 cells. Moreover, we found that STAT5 inhibitor specifically inhibited TA in K562 cells (Figure 3a).

In order to investigate whether STAT5 could activate the $h T E R T$ gene promoter, we examined $h T E R T$ promoter activation by STAT5 using a luciferase reporter assay. A $3.9 \mathrm{~kb}$ fragment of the human wild-type $h T E R T$ promoter was fused to the pGL3-basic luciferase reporter vector [35]. HeLa cells were transiently co-transfected with the $h T E R T$ full-length promoter construct (pGL3hTERT) and pMX-STAT5a or pMX-STAT5b, while empty vector was used as a control [36]. Activation of the $h T E R T$ promoter was measured by luciferase activity. HeLa cells transfected with STAT5a showed a 2.7-fold increase in luciferase activity compared to control cells, while the induction of luciferase activity in the presence of exogenous STAT5b was not statistically significant
(Figure 3b). This indicated that the $h T E R T$ promoter was significantly activated by STAT5a, but not STAT5b.

Next, we verified the importance of STAT5 in hTERT gene expression by siRNA assay. K562 cells were transfected with STAT5a siRNA, STAT5b siRNA or scramble siRNA, respectively. The ability and specificity of STAT5a and STAT5b siRNAs were first examined by immunoblotting. Figure 3c showed the scramble siRNA did not affect the expression of STAT5a or STAT5b. As shown in Figure 3c, when STAT5a protein level was $70 \%$ reduced, $h T E R T$ mRNA levels, together with TA, were clearly downregulated after $72 \mathrm{~h}$ of post-transfection with STAT5a siRNA, whereas the STAT5b siRNA, which reduced STAT5b protein level significantly by $80 \%$, did not affect $h T E R T$ mRNA levels as well as TA (Figure $3 d$ ). In agreement with these results, we also found knockdown of STAT5a, but not STAT5b, resulted in marked reduction in hTERT protein level (Figure 3c). When same experiments were carried out in HL60, BCR-ABL negative cells, STAT5a silencing showed no effect on $h T E R T$ mRNA expression and TA (Additional file 1: Figure S12).

Taken together, these data strongly suggested that activated STAT5a, but not STAT5b, plays a critical role in telomerase regulation in $\mathrm{K} 562$, BCR-ABL positive cells. These findings also indicated that BCR-ABL could 
A

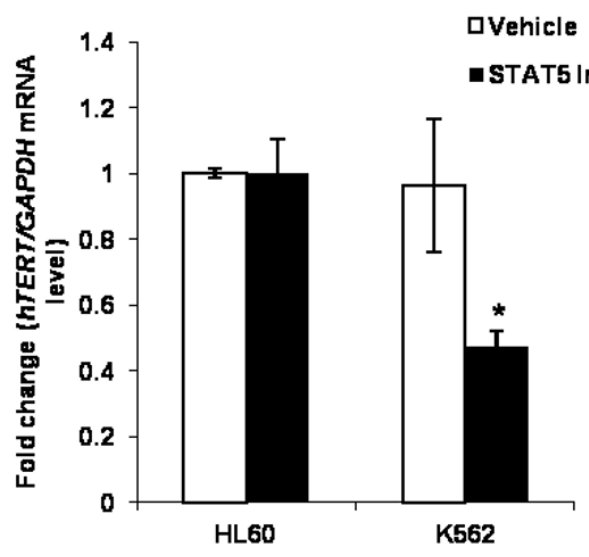

B

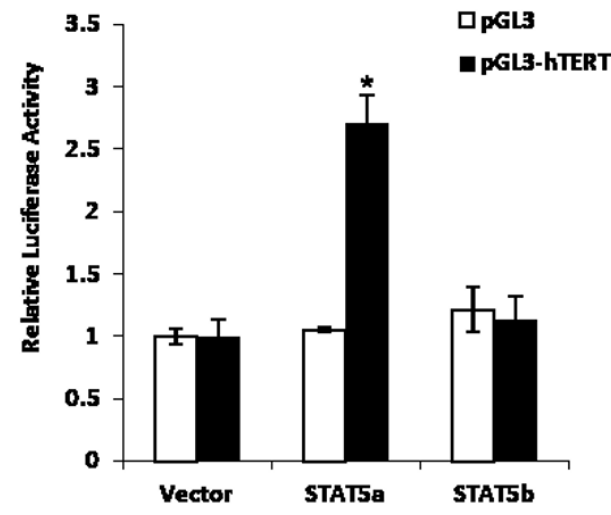

D

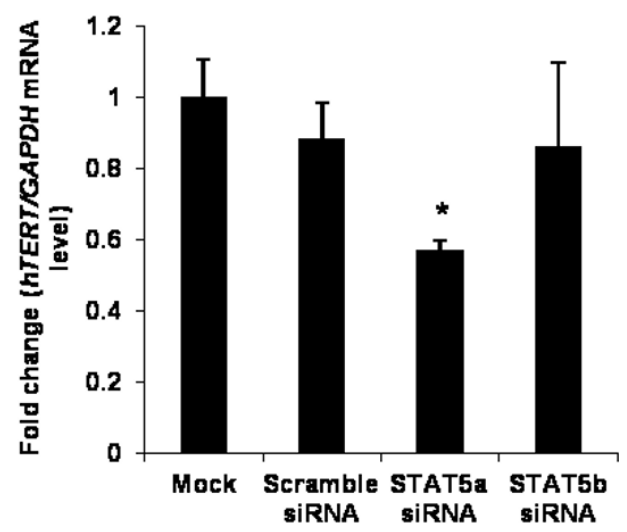

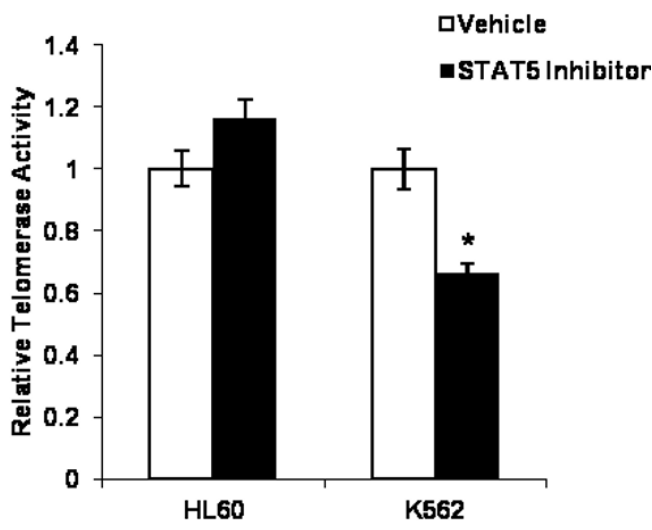

C

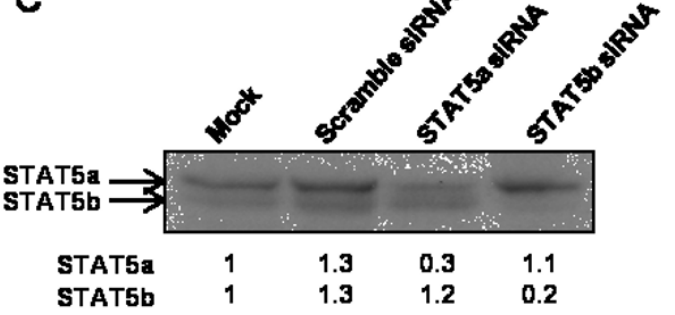

hTERT

hTERT

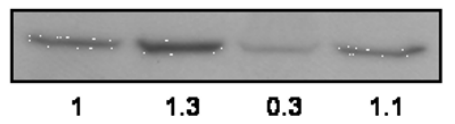

B-Actin

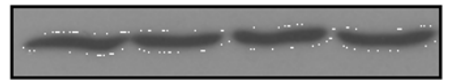

igure 3 STAT5a plays important role in hTERT mRNA expression. (a) HL60 and K562 cells were treated with vehicle (DMSO) Or STAT5 inhibitor $(50 \mu \mathrm{M})$ for $48 \mathrm{~h}$, after that cells were harvested. Expression of hTERT was measured using real-time PCR and normalized to the expression of GAPDH. TA was determined by quantitative telomerase assay. (b) K562 cells were co-transfected with empty vector (pGL3) or with a luciferase construct containing the hTERT promoter (pGL3-hTERT) together with empty expression vector (pMX) or STAT5a or STAT5b expression construct (pMX-STAT5a or pMX-STAT5b). Luciferase activity was determined $48 \mathrm{~h}$ after transfection and was normalized to empty expression vector. Each luciferase assay was repeated 3 times. (c) K562 cells were transfected with Scramble siRNA (non-targeting siRNA), STAT5a siRNA, STAT5b siRNA, or non-transfected (Mock). Cells were lysed after $72 \mathrm{~h}$ post-transfection. Total amount of STAT5a, STAT5b and hTERT were shown by Western blotting, and quantitated by normalization over the expression of $\beta$-Actin using ImageJ. (d) After 72 h post-transfection, K562 cells were collected and hTERT mRNA expression level and TA were measured by real-time PCR and quantitative telomerase assay, respectively 
regulate TA by transcriptional control of $h T E R T$ mRNA level through the JAK-STAT pathway.

\section{Gleevec regulates human TA and hTERT phosphorylation through inhibition of BCR-ABL kinase activity}

Some studies showed that protein kinase C (PKC) $\alpha$ and $\mathrm{AKT} /$ protein kinase $\mathrm{B}$ (PKB) can upregulate human TA through phosphorylation of hTERT [20,21]. Given that BCR-ABL functions as a tyrosine kinase, we questioned whether BCR-ABL could also directly enhance TA through phosphorylation of hTERT. To address this question, we analyzed the phosphorylation level of hTERT using anti-phosphotyrosine antibody in both BCR-ABL positive (K562) and BCR-ABL deficient (HL60) cells. Compared to HL60 cells, the tyrosine phosphorylation level in K562 cells was markedly increased (Figure 4a), suggesting that the increase in tyrosine phosphorylation is due to BCR-ABL tyrosine kinase activity, which was confirmed by the expression of BCR-ABL shown only in K562 cells. Interestingly, we found a significant increase in tyrosine-phosphorylation at the corresponding molecular weight of hTERT (122 $\mathrm{kDa}$ ) in K562 cells compared to HL60 cells. This result led us to consider that hTERT could be phosphorylated at tyrosine residues by BCR-ABL in K562 cells. To evaluate this possibility, hTERT was immunoprecipitated by anti-hTERT antibody from both K562 and HL60 cell lysates and resolved by SDS-PAGE followed by immunoblotting with anti-phosphorylation antibody. We found that hTERT tyrosine phosphorylation was significantly elevated in K562 cells compared to HL60 cells (Figure 4b). As the expression level of hTERT was similar in both cells, the result suggested that hTERT could be presumably phosphorylated by BCR-ABL.

To further determine whether BCR-ABL phosphorylates hTERT, we treated K562 cells with $1 \mu \mathrm{M}$ Gleevec, and evaluated the phosphorylation status of hTERT. If hTERT is a substrate of BCR-ABL, we would expect Gleevec treatment to decrease the phosphorylation level of hTERT and its activity. As shown in Figure 4c, Gleevec treatment resulted in almost complete inhibition of hTERT phosphorylation at tyrosine residues compared to control cells. To demonstrate that the decrease in tyrosine phosphorylation of hTERT was not due to reduced hTERT expression level, western blot was performed and we did not observe a difference in hTERT expression level in Gleevec-treated K562 cells compared to control cells (Figure 4c). We also examined the interaction between BCR-ABL and hTERT using immunoprecipitation assay. Surprisingly, there was no evidence of direct interaction between BCR-ABL and hTERT (data not shown).Overall, these results suggested that BCR-ABL can regulate TA by post-translational modification of hTERT through tyrosine phosphorylation.

\section{Gleevec inhibits hTERT nucleoli translocation in K562 BCR-ABL positive cells}

It is known that phosphorylation of hTERT is important for its nuclear translocation [37]. We subsequently examined the localization of hTERT in K562, HL60, and Jurkat with and without Gleevec treatment. Confocal microscopy was carried out to study Gleevec's effect on hTERT cellular distribution in K562, HL60, and Jurkat cells. These three cell lines were infected with GFPhTERT as the endogenous level of hTERT could not easily be detected in these cells by immunofluoresence microscopy. They were then either left untreated (Figure $5 \mathrm{a}, \mathrm{c}$ and $5 \mathrm{e}$ ) or treated with Gleevec for $16 \mathrm{~h}$ (Figure $5 b, d$ and $5 f$ ). Images were merged for two colors: GFPhTERT (green) and fibrillarin (red), the latter was used as a marker for nucleoli while the nucleus was stained with DAPI. A concentrated localization of hTERT was observed in nucleoli of non-treated K562 cells (Figure 5a and 5g), but not in HL60 and Jurkat cells (Figure 5c and $5 \mathrm{e})$. Gleevec treatment induced dissociation of hTERT from nucleoli of K562 cells to nucleoplasm (Figure $5 \mathrm{~b}$ ). This finding indicated that hTERT could partly have translocated into the nucleoplasm or was prevented from binding to nucleoli upon Gleevec treatment. In contrast, HL60 and Jurkat cells showed that hTERT was mainly dispersed in the nucleoplasm but not concentrated in nucleoli (Figure 5c-f).

\section{Discussion}

Previous studies have suggested that treatment of Gleevec could inhibit TA through suppressing hTERT mRNA level and hTERT phosphorylation level; the latter is regulated by serine/threonine protein kinase AKT $[20,21]$. However, the mechanism by which Gleevec inhibits TA in BCR-ABL positive cells remains largely unknown. Given the clinical significance of BCR-ABL in leukemia treatment, we sought to investigate the roles of BCR-ABL in CML and its relationship with telomerase regulation, in order to facilitate in the development of better anti-CML drugs. We found that Gleevec inhibits TA through BCR-ABL by two separate mechanisms: (1) by reducing the $h T E R T$ mRNA level via suppressing BCR-ABL mediated STAT5 signaling pathway; (2) by inhibiting phosphorylation of hTERT that can reduce TA and induce hTERT cellular translocation.

Our RT-PCR results showed that hTERT mRNA is dramatically reduced in the presence of Gleevec. The reduction of expression is only found in $h T E R T$ but not in $h T E R$ of telomerase in K562 cells. This implies that Gleevec only affects the catalytic component of telomerase. Moreover, Gleevec treatment of K562 cells resulted in a significant decrease in TA but has no effect on the processivity of the telomerase. Our results are consistent with previous findings that TA is inhibited in BCR- 


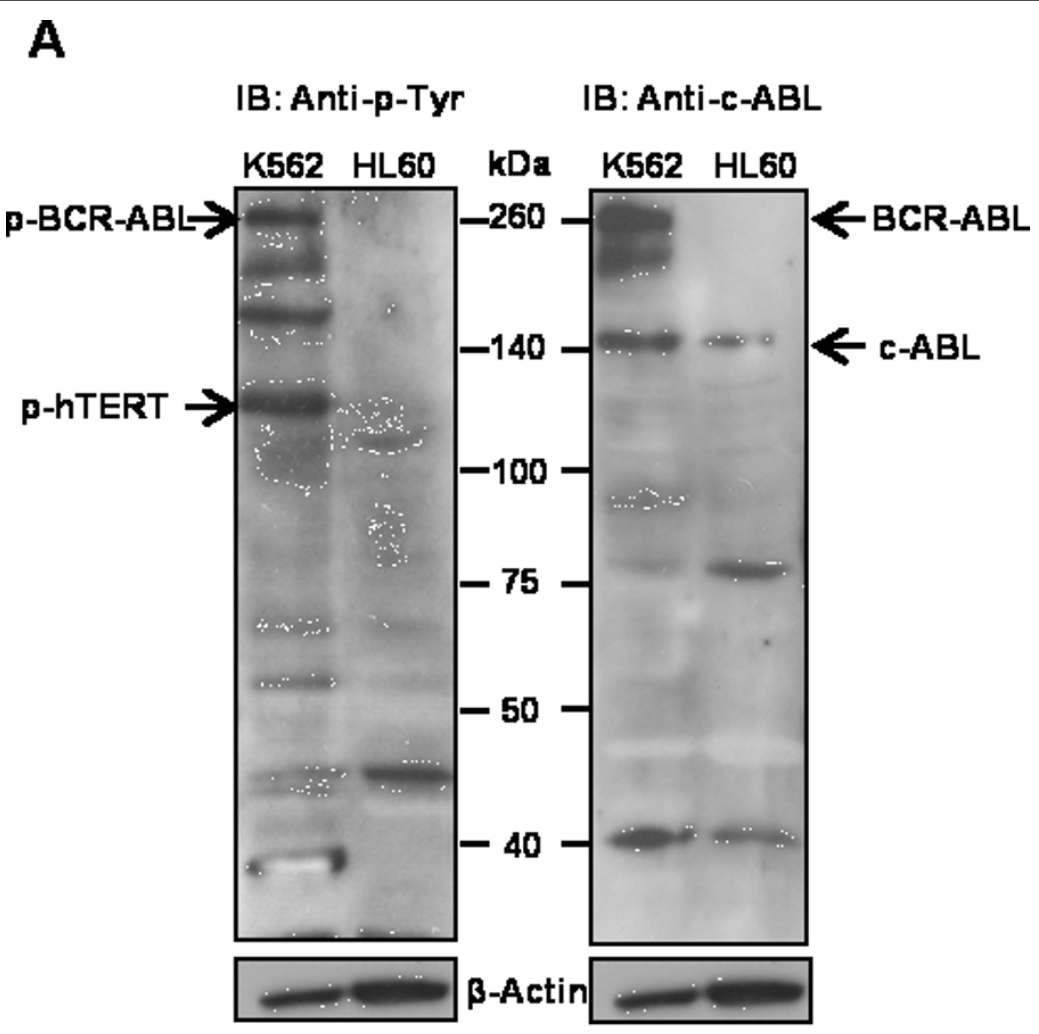

B

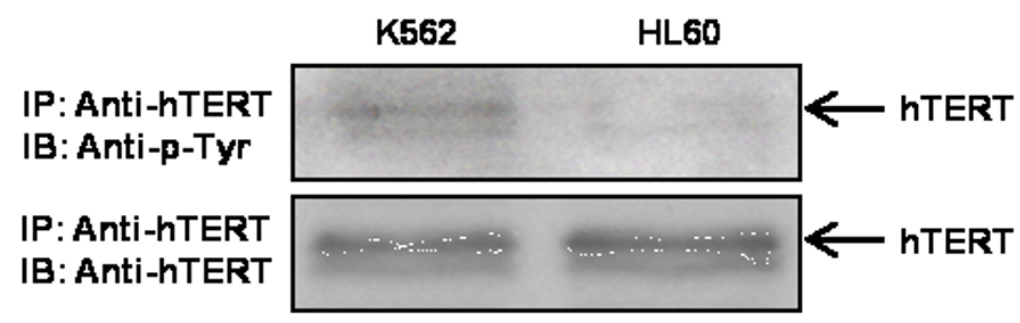

C

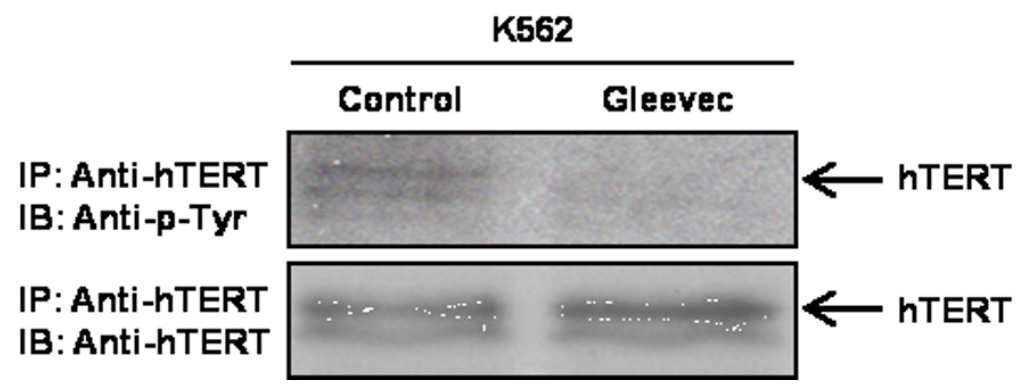

Figure 4 Post-translational regulation and phosphorylation of BCR-ABL on hTERT. (a) Global protein tyrosine-phosphorylation level and BCR-ABL expression in K562 and HL60 cells. (b) Phosphorylation of hTERT at tyrosine residues was higher in K562 cells compared to HL60 cells. (c) Gleevec treatment led to a loss of phosphorylation of hTERT at tyrosine residues 


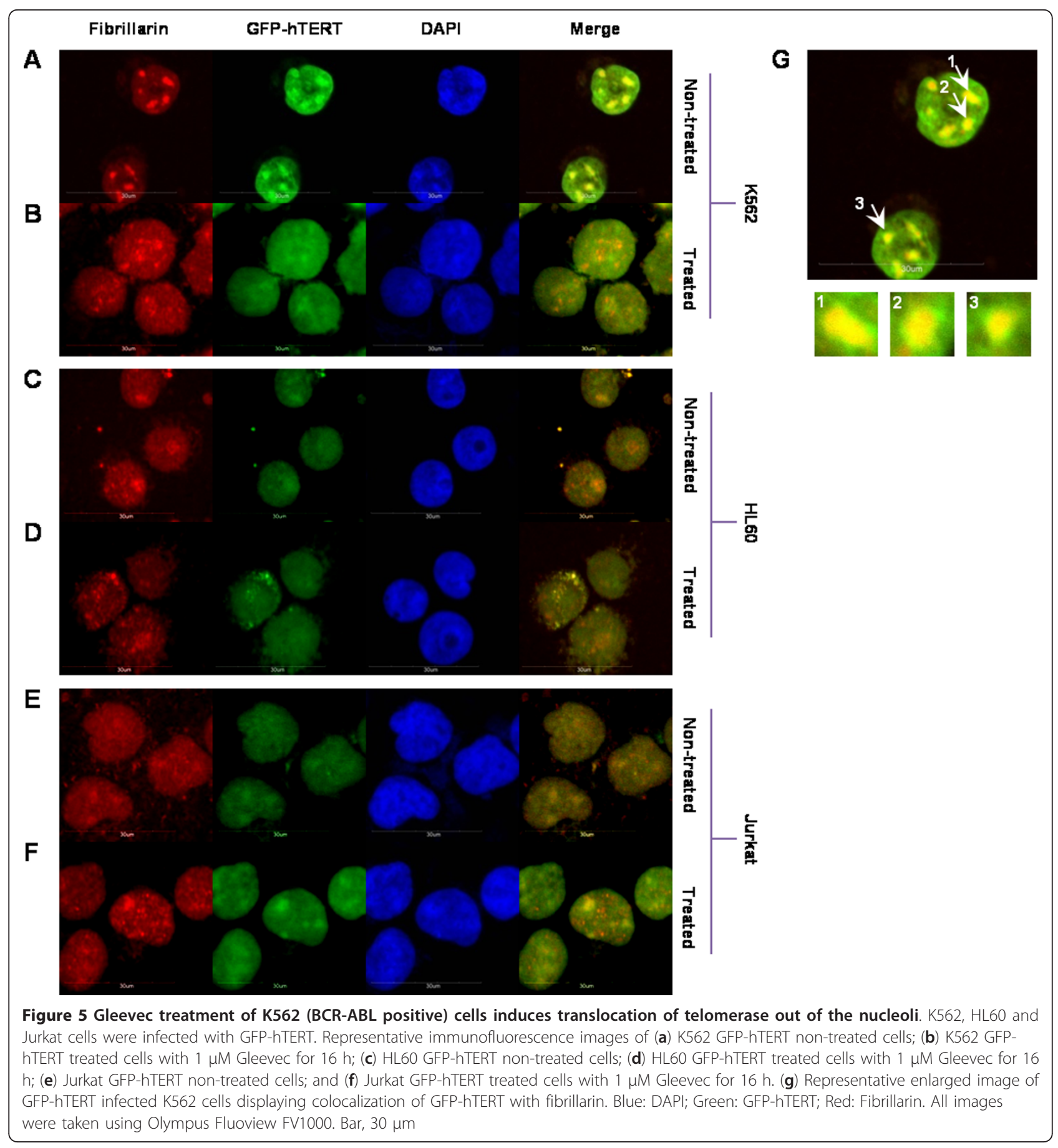

ABL-positive cells by Gleevec and this inhibition is specific to telomerase [25].

It is known that telomerase inhibition can reduce telomere length to a critical threshold resulting in senescence and/or apoptosis. We examined Gleevec's effect on telomere length in K562 cells and observed telomere shortening following 3 weeks of exposure to sub-apoptotic concentrations of Gleevec, while short-term
Gleevec treatment showed no significant effect on telomere length. The efficacy of long-term telomerase inhibition suggests that Gleevec may inhibit K562 cell growth and proliferation by modulating telomere length.

From the microarray analysis, we found that PI3K was downregulated in the JAK/STAT signaling pathway in Gleevec-treated K562 cells as compared to the K562 control group. Previous study has shown that BCR-ABL 
activates PI3Ks and extracellular signals to produce phosphatidylinositol-3,4,5-trisphosphate $\left(\mathrm{PIP}_{3}\right)$, which is a second messenger that activates and recruits downstream effector proteins such as the serine/threonine kinase AKT [38]. Thus, this suggests that the downregulation of PI3K is due to the inhibition of BCR-ABL tyrosine kinase activity via the JAK/STAT pathway upon Gleevec treatment in K562 cells, which may ultimately reduce $\mathrm{TA}$ in these cells.

STAT family proteins function as downstream effectors of a variety of cytokines and growth factors. STAT factors transmit signals to the nucleus where they bind to specific DNA promoter sequences and thereby regulate gene expression [39]. Numerous studies have demonstrated that constitutively activated STAT factors, particularly STAT3 and STAT5, have been found in a wide variety of human tumors, including blood malignancies (leukemias, lymphomas) [40,41]. Constitutively activated STAT factors are linked to persistent activity of tyrosine kinases, such as BCR-ABL, Src, and many others.

In this study, we observed and confirmed that STAT5 was phosphorylated only in BCR-ABL positive K562 cells and 2-hour Gleevec treatment completely abolished the phosphorylation of STAT5, which is in agreement with previous findings describing that STAT5 pathway is constitutively activated by p 210 BCR-ABL and p 190 BCR-ABL in leukemic cells [42,43]. BCR-ABL directly phosphorylates STAT5 at tyrosine residues and promotes dimerization of phosphorylated STAT5 followed by nuclear translocation of the dimers that then promote activation of downstream target genes, which are important to induce or maintain cancer cell growth and survival. A previous report showed that inhibition of BCR-ABL, as well as STAT5, by a selective inhibitor, suppressed cell proliferation and induced apoptosis in the BCR-ABL/STAT5 double positive K562 CML cell line, while this inhibitor had no effect on either a BCRABL-negative/STAT5-positive or a BCR-ABL/STAT5 double-negative myeloid cell line, suggesting that the STAT5 signaling pathway leading to growth and survival is BCR-ABL-dependent [44]. Some studies demonstrated that STAT5 activation is absolutely essential for leukemic cells because STAT5 activation leads to increased expression of genes driving cell cycle progression and promoting survival $[45,46]$, but it still remains unclear whether STAT5 is involved in regulating telomerase, which plays critical role in tumor cell growth and proliferation.

We present here several lines of evidence for a role of STAT5 in telomerase regulation in BCR-ABL positive K562 cells. We have shown that Gleevec treatment reduced STAT5 phosphorylation, which coincides with a decrease in $h T E R T$ mRNA expression. We also found that STAT5 inhibitor selectively suppressed $h T E R T$ mRNA expression and TA in BCR-ABL positive K562 cells. It has been known that STAT5 comprises of two highly homologous genes encoding STAT5a and STAT5b [47]. Although these two STAT proteins share considerable functional overlap, gene-disruption experiments have revealed that STAT5a and STAT5b are functionally not redundant $[48,49]$. Previous studies demonstrated that STAT5a mediates prolactin signaling along with mammary gland development $[48,50]$, whereas knockdown of STAT5b abrogates sexually dimorphic liver gene regulation and is associated with loss of male characteristic body growth rates [51]. In this study, we demonstrated that STAT5a, but not STAT5b, expression and phosphorylation correlated with $h T E R T$ gene expression and TA. More importantly, knockdown of STAT5a as well as Gleevec treatment severely reduced $h T E R T$ gene expression and TA in BCR-ABL positive K562 cells but not in BCR-ABL negative HL60 cells. These results strongly support the notion that constitutive activation of STAT5a is likely to make a significant contribution to the telomerase regulation in BCR-ABL positive CML cells, suggesting that STAT5a could be an attractive target for the treatment of CML, especially in cases of multiple inhibitor-resistant CML. Our findings are in accordance with recent reports which demonstrated that STAT5 accounts for the resistance against Gleevec and inhibition of STAT5 can effectively decrease survival of CML cells resistant to tyrosine kinase inhibitors [52,53].

It is known that protein phosphorylation is an important post-translational regulation controlling protein structure and function [54]. Some reports indicated that PKC can stimulate TA through phosphorylation of hTERT, while TA was markedly inhibited in the presence of protein phosphatase 2A (PP2A) [55]. These findings suggest that PKC and PP2A are involved in reciprocally controlling $\mathrm{TA}$ through phosphorylation and dephosphorylation. In addition to PKC, AKT was also found to phosphorylate the serine residue at position 824 of hTERT and stimulate TA [20]. In our study, immunoprecipitation assay demonstrated that the hTERT tyrosine phosphorylation level was higher in K562 cells compared to HL60 cells and Gleevec treatment could effectively abrogate hTERT tyrosine phosphorylation in $\mathrm{K} 562$ cells as well as TA inhibition, suggesting that BCR-ABL could also phosphorylate hTERT and this phosphorylation may be important for TA maintenance and regulation. However, further investigations are necessary to determine which tyrosine could be the substrate of BCR-ABL. Previous results demonstrated that $\mathrm{c}-\mathrm{ABL}$, a non-receptor tyrosine kinase, can directly interact with hTERT and inhibit TA following phosphorylation of hTERT [56]. This suggests 
that $\mathrm{c}-\mathrm{ABL}$ plays a negative role in regulating telomerase function and as such we determined whether $\mathrm{c}-\mathrm{ABL}$ could affect TA and hTERT protein level in $\mathrm{c}-\mathrm{ABL}^{-/-}$ mouse embryonic fibroblasts (MEFs). We found that there was no significant effect on TA and hTERT expression by the $\mathrm{c}-\mathrm{ABL}$ deficiency (Additional file 1: Figure S13).

Previously, Liu and colleagues reported that phosphorylation of hTERT may be an important mechanism to regulate hTERT subcellular translocation from the cytosol to the nucleus [37]. Presumably, the translocation of hTERT from a non-functional cytosolic location to a physiologically relevant nuclear location may play an important role in regulating TA in cells. As we revealed here that hTERT could be phosphorylated by BCR-ABL, we next questioned whether BCR-ABL could also govern hTERT translocation in different cellular compartments. Our confocal images have shown that hTERT in K562 BCR-ABL positive cells were localized and concentrated in nucleoli at normal conditions. Under Gleevec treatment, most of the hTERT dissociated from nucleoli into the nucleoplasm. In contrast, this phenomenon was not observed in HL60 and Jurkat, BCR-ABL deficient cells. This implies that Gleevec treatment could possibly inhibit phosphorylation of hTERT, induce hTERT translocation and thereby decrease telomerase enzyme assembly and subsequent activity.

We suppose that hTERT could be phosphorylated by BCR-ABL directly since hTERT tyrosine phosphorylation level was found elevated in $\mathrm{K} 562$ cells by immunoprecipitation assay (Figure 4b). In addition, the expression level of hTERT was similar in both cells. This result suggests that hTERT could be phosphorylated by BCR-ABL. Moreover, as shown in Figure 4c, Gleevec treatment resulted in near-elimination of hTERT phosphorylation at tyrosine residues compared to control. We also demonstrated that the decrease in tyrosine phosphorylation of hTERT was not due to reduced hTERT expression level (Figure 4c). However, our immunoprecipitation results showed that neither cABL nor BCR-ABL interacts with hTERT directly, which contradicts to a previous study that reported the association of c-ABL with hTERT [56]. This may due to the low affinity binding of BCR-ABL to hTERT or their transient interaction. A previous study has shown that $\mathrm{BCR}-\mathrm{ABL}$ is a large protein mainly found in the cytoplasm, whereas hTERT is mostly localized in the nucleus, excluding the possibility of a direct association between the two proteins [25]. This also implies that there may be another indirect regulation of $\mathrm{BCR}-\mathrm{ABL}$ on hTERT, which may require alternative pathways or through some other intermediate proteins.

Taken together, we show here that BCR-ABL inhibition by Gleevec treatment has a significant impact on telomerase regulation based on our findings (Figure 6). Our study reveals a link between transcription factor STAT5a and hTERT gene expression in BCR-ABL positive CML cell lines. Inhibition of BCR-ABL, and thus STAT5a, by Gleevec leads to reduced TA and $h T E R T$ mRNA expression as well as downregulation of hTERT phosphorylation at tyrosine residues at the post-translational level. In addition to that, we also found that BCRABL might regulate TA through the Wnt signaling pathway (unpublished data). These findings support the notion that telomerase expression and activity could be regulated at multiple levels by the same protein. Shuttling of telomerase in and out of nucleoli induced by Gleevec treatment provides a new insight on $B C R-A B L$ regulated TA.

The introduction of Gleevec has revolutionized the treatment of CML. Despite significant hematologic and cytogenetic responses, there has been concern over the emergence of resistance to Gleevec, which is mostly due to point mutations in the BCR-ABL kinase domain. One such mutation, T315I, renders CML cells completely resistant not only to Gleevec but also to second generation BCR-ABL inhibitors nilotinib and dasatinib [57]. This has spurred the interest in developing novel tyrosine kinase inhibitors or treatment strategies to overcome the mechanisms of resistance that have led to treatment failures. Our findings showed that STAT5, more particularly, STAT5a, plays a critical role in TA regulation, suggesting that inhibition of STAT5a in combination with $\mathrm{BCR}-\mathrm{ABL}$ may provide an alternative approach for treatment of leukaemia, especially in patients who are resistant to tyrosine inhibitors.

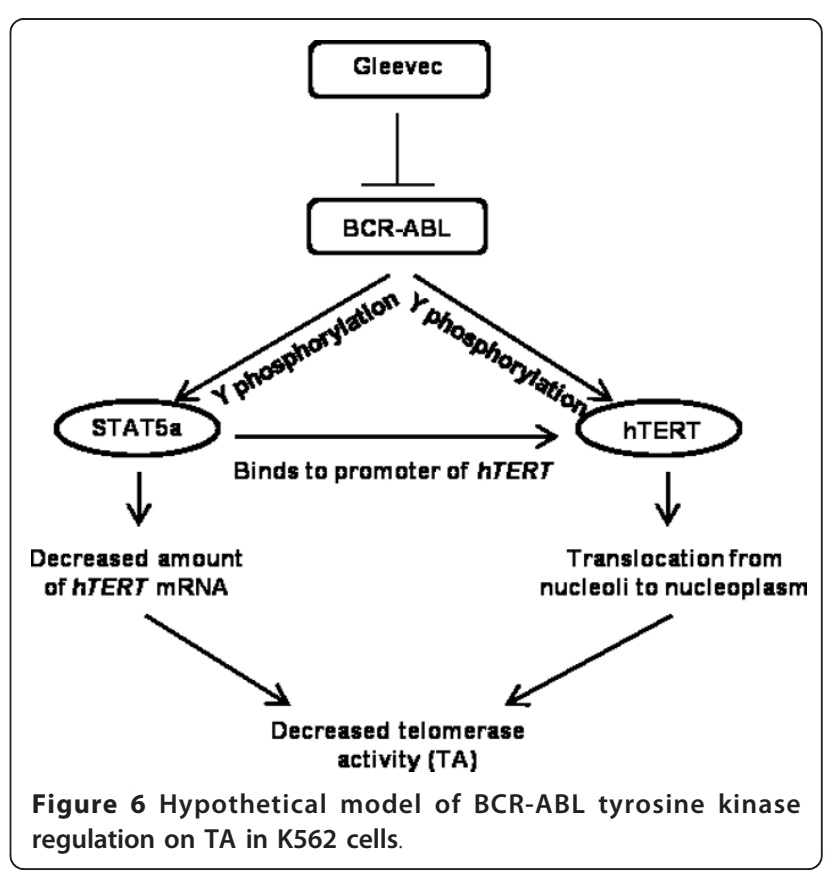


Knockdown and inhibition of constitutively active STAT5 has been implicated in growth suppression in CML cells but not in normal cells [58,59]. Such a combination may allow less dose of each drug, and therefore decrease side effects. More importantly, this strategy can decrease the emergence of drug-resistant cells.

\section{Conclusions}

Our data suggest that BCR-ABL can regulate TA at multiple levels, including transcription, post-translational level, and proper localization. Therefore, suppression of cell growth and induction of apoptosis by Gleevec treatment may be partially due to TA inhibition. More importantly, we have identified STAT5a as critical mediator of the $h T E R T$ gene expression in BCRABL positive CML cells, suggesting that targeting STAT5a may be a promising therapeutic strategy for BCR-ABL positive CML patients, especially for resistant cases due to mutants of BCR-ABL.

\section{Additional material}

Additional file 1: Supplemental data. Regulation of hTERT by BCR-ABL at multiple levels in K562 cells.

\begin{abstract}
Abbreviations
TA: telomerase activity; CML: chronic myeloid leukemia; ALL: acute lymphoblastic; leukemia; BCR: breakpoint cluster region; TRAP: telomeric repeat amplification protocol; STELA: single telomere length assay; Ph: Philadelphia chromosome
\end{abstract}

\section{Acknowledgements and funding}

The plasmids (pMX-STAT5a and pMX-STAT5b) were a kind gift from Prof. Manfred Schartl (Universität Würzburg). We thank Dr. Motomi Osato for generous sharing of cell lines including KU812. We thank Dr. Jianbiao Zhou, Dashayini Mahalingam, and Ling Lee Tay for technical support. We also thank Dr. Gregory Bellot Lucien for critical reading of the manuscript. This work is supported by the Department of Biochemistry and Cancer Science Institute of Singapore, National University of Singapore. Dr Xueying Wang acknowledges funding support from the Academic Research Fund Tier 1 Faculty Research Committee grant at the National University of Singapore and the National Medical Research Council grant NMRC/EDG/0058/2009, Singapore. The funders had no role in study design, data collection and analysis, decision to publish, or preparation of the manuscript.

\section{Author details \\ 'Department of Biochemistry, Yong Loo Lin School of Medicine, National University of Singapore, 8 Medical Drive, 117597 Singapore, Singapore. 2Department of Biochemistry, Yong Loo Lin School of Medicine, Cancer Science Institute of Singapore (CSI), National University of Singapore, Singapore, Singapore. ${ }^{3}$ Department of Medicine, Yong Loo Lin School of Medicine, National University of Singapore, Singapore, Singapore. ${ }^{4}$ Department of Haematology-Oncology, National University Cancer Institute of Singapore, National University Health System, Singapore, Singapore. ${ }^{5}$ Bio-X Center, Key Laboratory for the Genetics of Developmental and Neuropsychiatric Disorders, Ministry of Education, Shanghai Jiao Tong University, Shanghai, People's Republic of China.}

\section{Authors' contributions}

JHC, YZ and WHT carried out the experiments. JHC, YZ and XW participated in the design of the study, its coordination, and helped to draft the manuscript. In addition, technical guidance from WJC, BL and XW lead to successful experiments. All authors approved the final manuscript.

\section{Competing interests}

The authors declare that they have no competing interests.

Received: 19 July 2011 Accepted: 9 December 2011

Published: 9 December 2011

\section{References}

1. Nowell PC: Discovery of the Philadelphia chromosome: a personal perspective. J Clin Invest 2007, 117(8):2033-2035.

2. Shtivelman E, Lifshitz B, Gale RP, Roe BA, Canaani E: Alternative splicing of RNAs transcribed from the human abl gene and from the bcr-abl fused gene. Cell 1986, 47(2):277-284.

3. Clark SS, McLaughlin J, Timmons M, Pendergast AM, Ben-Neriah Y, Dow LW, Crist W, Rovera G, Smith SD, Witte ON: Expression of a distinctive BCR-ABL oncogene in Ph1-positive acute lymphocytic leukemia (ALL). Science 1988, 239(4841 Pt 1):775-777.

4. Rowley JD: Letter: A new consistent chromosomal abnormality in chronic myelogenous leukaemia identified by quinacrine fluorescence and Giemsa staining. Nature 1973, 243(5405):290-293.

5. Butturini A, Arlinghaus RB, Gale RP: BCR/ABL. Encyclopedia of Cancer 2002, 1:6.

6. Melo JV, Barnes DJ: Chronic myeloid leukaemia as a model of disease evolution in human cancer. Nat Rev Cancer 2007, 7(6):441-453.

7. Mandanas RA, Leibowitz DS, Gharehbaghi K, Tauchi T, Burgess GS, Miyazawa K, Jayaram HN, Boswell HS: Role of p21 RAS in p210 bcr-abl transformation of murine myeloid cells. Blood 1993, 82(6):1838-1847.

8. Skorski T, Bellacosa A, Nieborowska-Skorska M, Majewski M, Martinez R, Choi JK, Trotta R, Wlodarski P, Perrotti D, Chan TO, et al: Transformation of hematopoietic cells by BCR/ABL requires activation of a Pl-3 k/Aktdependent pathway. EMBO J 1997, 16(20):6151-6161.

9. Raitano AB, Halpern JR, Hambuch TM, Sawyers CL: The Bcr-Abl leukemia oncogene activates Jun kinase and requires Jun for transformation. Proc Natl Acad Sci USA 1995, 92(25):11746-11750.

10. Sawyers $C L$, Callahan W, Witte ON: Dominant negative MYC blocks transformation by ABL oncogenes. Cell 1992, 70(6):901-910.

11. Lugo TG, Pendergast AM, Muller AJ, Witte ON: Tyrosine kinase activity and transformation potency of bcr-abl oncogene products. Science 1990, 247(4946):1079-1082.

12. Druker BJ, Tamura S, Buchdunger E, Ohno S, Segal GM, Fanning S, Zimmermann J, Lydon NB: Effects of a selective inhibitor of the Abl tyrosine kinase on the growth of Bcr-Abl positive cells. Nat Med 1996, 2(5):561-566.

13. John S: The molecular biology of cancer. Molecular Aspects of Medicine 2001, 21:57.

14. O'Dwyer ME, Gatter KM, Loriaux M, Druker BJ, Olson SB, Magenis RE, Lawce H, Mauro MJ, Maziarz RT, Braziel RM: Demonstration of Philadelphia chromosome negative abnormal clones in patients with chronic myelogenous leukemia during major cytogenetic responses induced by imatinib mesylate. Leukemia 2003, 17(3):481-487.

15. Cohen SB, Graham ME, Lovrecz GO, Bache N, Robinson PJ, Reddel RR: Protein composition of catalytically active human telomerase from immortal cells. Science 2007, 315(5820):1850-1853.

16. Shay JW, Keith WN: Targeting telomerase for cancer therapeutics. Br J Cancer 2008, 98(4):677-683.

17. Bock O, Serinsoz E, Schlue J, Kreipe H: Different expression levels of the telomerase catalytic subunit hTERT in myeloproliferative and myelodysplastic diseases. Leuk Res 2004, 28(5):457-460.

18. Hahn WC, Counter CM, Lundberg AS, Beijersbergen RL, Brooks MW, Weinberg RA: Creation of human tumour cells with defined genetic elements. Nature 1999, 400(6743):464-468.

19. Aisner DL, Wright WE, Shay JW: Telomerase regulation: not just flipping the switch. Curr Opin Genet Dev 2002, 12(1):80-85.

20. Kang SS, Kwon T, Kwon DY, Do Sl: Akt protein kinase enhances human telomerase activity through phosphorylation of telomerase reverse transcriptase subunit. J Biol Chem 1999, 274(19):13085-13090.

21. Liu JP: Studies of the molecular mechanisms in the regulation of telomerase activity. FASEB J 1999, 13(15):2091-2104. 
22. Lankat-Buttgereit B, Horsch D, Barth P, Arnold R, Blocker S, Goke R: Effects of the tyrosine kinase inhibitor imatinib on neuroendocrine tumor cell growth. Digestion 2005, 71(3):131-140.

23. Uziel O, Fenig E, Nordenberg J, Beery E, Reshef H, Sandbank J, Birenbaum M, Bakhanashvili M, Yerushalmi R, Luria D, et al: Imatinib mesylate (Gleevec) downregulates telomerase activity and inhibits proliferation in telomerase-expressing cell lines. $\mathrm{Br} J$ Cancer 2005, 92(10):1881-1891.

24. Wihlidal P, Karlic H, Pfeilstocker M, Klaushofer K, Varga F: Imatinib mesylate (IM)-induced growth inhibition is associated with production of spliced osteocalcin-mRNA in cell lines. Leuk Res 2008, 32(3):437-443.

25. Mor-Tzuntz R, Uziel O, Shpilberg O, Lahav J, Raanani P, Bakhanashvili M, Rabizadeh E, Zimra Y, Lahav M, Granot G: Effect of imatinib on the signal transduction cascade regulating telomerase activity in K562 (BCR-ABLpositive) cells sensitive and resistant to imatinib. Exp Hematol 2010, 38(1):27-37.

26. Campbell LJ, Fidler C, Eagleton H, Peniket A, Kusec R, Gal S, Littlewood TJ, Wainscoat JS, Boultwood J: hTERT, the catalytic component of telomerase, is downregulated in the haematopoietic stem cells of patients with chronic myeloid leukaemia. Leukemia 2006, 20(4):671-679.

27. Phatak $P$, Burger AM: Telomerase and its potential for therapeutic intervention. Br J Pharmacol 2007, 152(7):1003-1011.

28. Baird DM, Rowson J, Wynford-Thomas D, Kipling D: Extensive allelic variation and ultrashort telomeres in senescent human cells. Nat Genet 2003, 33(2):203-207.

29. Opitz OG: Telomeres, telomerase and malignant transformation. Curr Mol Med 2005, 5(2):219-226.

30. Capdeville R, Buchdunger E, Zimmermann J, Matter A: Glivec (STI571, imatinib), a rationally developed, targeted anticancer drug. Nat Rev Drug Discov 2002, 1(7):493-502.

31. Hartmann U, Balabanov S, Ziegler P, Fellenberg J, van der Kuip H, Duyster J, Lipp HP, Bokemeyer C, Kanz L, Brummendorf TH: Telomere length and telomerase activity in the BCR-ABL-transformed murine pro- $B$ cell line $\mathrm{BaF} 3$ is unaffected by treatment with imatinib. Experimental Hematology 2005, 33(5):542-549.

32. Yi X, Shay JW, Wright WE: Quantitation of telomerase components and hTERT mRNA splicing patterns in immortal human cells. Nucleic Acids Res 2001, 29(23):4818-4825

33. Bellon M, Nicot C: Central role of PI3K in transcriptional activation of hTERT in HTLV-I-infected cells. Blood 2008, 112(7):2946-2955.

34. Nakatake M, Kakiuchi Y, Sasaki N, Murakami-Murofushi K, Yamada O: STAT3 and PKC differentially regulate telomerase activity during megakaryocytic differentiation of K562 cells. Cell Cycle 2007, 6(12):1496-1501

35. Horikawa I, Cable PL, Mazur SJ, Appella E, Afshari CA, Barrett JC: Downstream E-box-mediated regulation of the human telomerase reverse transcriptase (hTERT) gene transcription: evidence for an endogenous mechanism of transcriptional repression. Mol Biol Cell 2002, 13(8):2585-2597.

36. Wellbrock C, Weisser C, Hassel JC, Fischer P, Becker J, Vetter CS, Behrmann I, Kortylewski M, Heinrich PC, Schartl M: STAT5 contributes to interferon resistance of melanoma cells. Curr Biol 2005, 15(18):1629-1639.

37. Liu K, Hodes RJ, Weng N: Cutting edge: telomerase activation in human $\mathrm{T}$ lymphocytes does not require increase in telomerase reverse transcriptase (hTERT) protein but is associated with hTERT phosphorylation and nuclear translocation. J Immunol 2001, 166(8):4826-4830.

38. Kharas MG, Janes MR, Scarfone VM, Lilly MB, Knight ZA, Shokat KM, Fruman DA: Ablation of PI3K blocks BCR-ABL leukemogenesis in mice, and a dual PI3K/mTOR inhibitor prevents expansion of human BCR-ABL + leukemia cells. J Clin Invest 2008, 118(9):3038-3050.

39. Darnell JE Jr, Kerr IM, Stark GR: Jak-STAT pathways and transcriptional activation in response to IFNs and other extracellular signaling proteins. Science 1994, 264(5164):1415-1421.

40. Bowman T, Garcia R, Turkson J, Jove R: STATs in oncogenesis. Oncogene 2000, 19(21):2474-2488.

41. Ye D, Wolff N, Li L, Zhang SM, llaria RL: STAT5 signaling is required for the efficient induction and maintenance of CML in mice. Blood 2006, 107(12):4917-4925
42. Ilaria RL Jr, Van Etten RA: P210 and P190(BCR/ABL) induce the tyrosine phosphorylation and DNA binding activity of multiple specific STAT family members. J Biol Chem 1996, 271(49):31704-31710.

43. Shuai K, Halpern J, ten Hoeve J, Rao X, Sawyers CL: Constitutive activation of STAT5 by the BCR-ABL oncogene in chronic myelogenous leukemia. Oncogene 1996, 13(2):247-254.

44. Decker T, Kovarik P: Transcription factor activity of STAT proteins: structural requirements and regulation by phosphorylation and interacting proteins. Cell Mol Life Sci 1999, 55(12):1535-1546.

45. Hoelbl A, Schuster C, Kovacic B, Zhu BM, Wickre M, Hoelzl MA, Fajmann S, Grebien F, Warsch W, Stengl G, et al: Stat5 is indispensable for the maintenance of bcr/abl-positive leukaemia. EMBO Molecular Medicine 2010, 2(3):98-110.

46. Sillaber C, Gesbert F, Frank DA, Sattler M, Griffin JD: STAT5 activation contributes to growth and viability in Bcr/Abl-transformed cells. Blood 2000, 95(6):2118-2125.

47. Lin JX, Leonard WJ: The role of Stat5a and Stat5b in signaling by IL-2 family cytokines. Oncogene 2000, 19(21):2566-2576.

48. Teglund S, McKay C, Schuetz E, van Deursen JM, Stravopodis D, Wang DM Brown M, Bodner S, Grosveld G, Ihle JN: Stat5a and Stat5b proteins have essential and nonessential, or redundant, roles in cytokine responses. Cell 1998, 93(5):841-850.

49. Socolovsky M, Fallon AEJ, Wang S, Brugnara C, Lodish HF: Fetal anemia and apoptosis of red cell progenitors in Stat $5 \mathrm{a}(-/-) 5 \mathrm{~b}(-/-)$ mice: A direct role for Stat5 in Bcl-X-L induction. Cell 1999, 98(2):181-191.

50. Liu XW, Robinson GW, Wagner KU, Garrett L, WynshawBoris A, Hennighausen L: Stat5a is mandatory for adult mammary gland development and lactogenesis. Gene Dev 1997, 11(2):179-186.

51. Park SH, Liu X, Hennighausen L, Davey HW, Waxman DJ: Distinctive roles of STAT5a and STAT5b in sexual dimorphism of hepatic P450 gene expression. Impact of STAT5a gene disruption. J Biol Chem 1999, 274(11):7421-7430

52. Nelson EA, Walker SR, Weisberg E, Bar-Natan M, Barrett R, Gashin LB, Terrell S, Klitgaard JL, Santo L, Addorio MR, et al: The STAT5 inhibitor pimozide decreases survival of chronic myelogenous leukemia cells resistant to kinase inhibitors. Blood 2011, 117(12):3421-3429.

53. Warsch W, Kollmann K, Eckelhart E, Fajmann S, Cerny-Reiterer S, Holbl A, Gleixner KV, Dworzak M, Mayerhofer M, Hoermann G, et al: High STAT5 levels mediate imatinib resistance and indicate disease progression in chronic myeloid leukemia. Blood 2011, 117(12):3409-3420.

54. Liu JP: Protein phosphorylation events in exocytosis and endocytosis. Clin Exp Pharmacol Physiol 1997, 24(8):611-618.

55. Li H, Zhao LL, Funder JW, Liu JP: Protein phosphatase $2 A$ inhibits nuclear telomerase activity in human breast cancer cells. J Biol Chem 1997, 272(27):16729-16732

56. Kharbanda S, Kumar V, Dhar S, Pandey P, Chen C, Majumder P, Yuan ZM, Whang Y, Strauss W, Pandita TK, et al: Regulation of the hTERT telomerase catalytic subunit by the c-Abl tyrosine kinase. Curr Biol 2000, 10(10):568-575.

57. Bradeen HA, Eide CA, O'Hare T, Johnson KJ, Willis SG, Lee FY, Druker BJ, Deininger MW: Comparison of imatinib mesylate, dasatinib (BMS354825), and nilotinib (AMN107) in an N-ethyl-N-nitrosourea (ENU)based mutagenesis screen: high efficacy of drug combinations. Blood 2006, 108(7):2332-2338.

58. Scherr M, Chaturvedi A, Battmer K, Dallmann I, Schultheis B, Ganser A, Eder M: Enhanced sensitivity to inhibition of SHP2, STAT5, and Gab2 expression in chronic myeloid leukemia (CML). Blood 2006, 107(8):3279-3287.

59. Donato NJ, Wu JY, Zhang L, Kantarjian H, Talpaz M: Down-regulation of interleukin-3/granulocyte-macrophage colony-stimulating factor receptor beta-chain in BCR-ABL(+) human leukemic cells: association with loss of cytokine-mediated Stat-5 activation and protection from apoptosis after BCR-ABL inhibition. Blood 2001, 97(9):2846-2853.

\section{Pre-publication history}

The pre-publication history for this paper can be accessed here: http://www.biomedcentral.com/1471-2407/11/512/prepub

doi:10.1186/1471-2407-11-512

Cite this article as: Chai et al.: Regulation of hTERT by BCR-ABL at multiple levels in K562 cells. BMC Cancer 2011 11:512. 